\title{
DESAIN MEDIA PENYULUHAN UNTUK PENYULUH PERTANIAN BERBASIS WEBSITE DI KECAMATAN BERBAK KABUPATEN TANJUNG JABUNG TIMUR
}

\author{
Pera Nurfathiyah ${ }^{1} 1$, Jamaluddin ${ }^{2}$ \\ Email : pera_nur@unja.ac.id
}

\begin{abstract}
Abstrak
Penelitian ini dilakukan untuk untuk mendapatkan desain media penyuluhan bagi penyuluh pertanian berbasis website tentang program percetakan sawah baru dan meningkatkan motivas penyuluh pertanian dalam memberikan materi penyuluhan kepada petani tentang program percetakan sawah baru di kecamatan Berbak kabupaten Tanjung Jabung Timur.Target yang akan dicapai dari penelitian ini adalah mendapatkan media penyuluhan yang dapat meningkatka motivasi penyuluh dalam memberikan penyuluhan dan sebagai alat bantu penyuluh dalam dalam kegiatan penyuluhan.

Metode Penelitian ini menggunakan metode Research and Development (penelitian dan pengembangan) dapat diartikan sebagai suatu proses atau langkah-langkah untuk mengembangkan suatu produk baru. Tahapan awal yaitu analisis dan perancangan media, tahapan pembuatan (pengembangan) dan tahapan evaluasi media. Teknik analisis data menggunakan teknik triangulasi yaitu data yang telah dikumpulkan disesuaikan dengan kebutuhan analisis, selanjutnya dilakukan analisis dengan menggunakan triangulasi sumber yaitu mengumpulkan saran dan pendapat dari 2 orang tim penilai tentang media yang telah dirancang. Data ini akan digunakan untuk memperbaiki media yang akan digunakan oleh penyuluh dalam kegiatan penyuluhan. Desain uji coba media menggunakan Adobe Flash CS4 professional.

Hasil penelitian disimpulkan bahwa Desain media penyuluhan berbasis website tentang program percetakan sawah baru untuk penyuluhan pertanian di kecamatan Berbak kabupaten Tanjung Jabung Timur yang paling efektif untuk meningkatkan motivasi penyuluh dalam memberikan penyuluhan adalah menggunakan gabungan teks, gambar, suara, grafik, warna dan animasi atau desain multimedia berbasis website. Fasilitas yang ada pada website menu beranda, program, informasi, kontak kami dan log in.

Kata kunci : Media penyuluhan, website, penyuluhan pertanian, program percetakan sawah baru
\end{abstract}

\section{PENDAHULUAN}

\section{Latar Belakang}

Kemajuan teknologi dewasa ini menjadikan informasi sebagai modal dasar bagi perkembangan sektor pertanian dimasa yang akan datang. Menurut Saleh (2000) informasi menjadi salah satu faktor produksi pertanian selain lahan, tenaga kerja dan modal. Informasi menjadi kebutuhan utamabagi penyuluh pertanian sebagai bahan diskusi dengan petani pada saat kegiatan penyuluhan. Dengan demikian seorang penyuluh yang handal sebelum melakukan kegiatan penyuluhan harus mampu mempersiapkan materi penyuluhan yang akan disampaikan kepada petani tentang inovasi baru yang disesuaikan dengan potensi daerah. Salah satu alat bantu yang dapat membantu penyuluh pertanian dalam mendapatkan informasi pertanian adalah media informasi berbasis website.

Media informasi berbasis websitedapat digunakan untuk menjembatani informasi dan pengetahuan yang tersebar di antara yang menguasai informasi dan yang tidak. Akses terhadap komunikasi melalui media website dapat membantu penyuluh pertanian dalam mendapatkan informasi dengan jangkauan yang sangat luas sehingga akses data dan informasi tidak terbatas oleh waktu, tempat dan negara. Media website yang diakses melalui internet lebih cepat hanya dengan memasukkan kata kunci yang dicari maka akan ditemukan informasi yang dicari, sehingga dapat meningkatkan

\footnotetext{
${ }^{1}$ Ketua Peneliti, dosen jurusan agribisnis Fakultas Pertanian Universitas Jambi

${ }^{2}$ Anggota Peneliti, dosen jurusan agribisnis Fakultas Pertanian Universitas Jambi
} 
kemampuanpenyuluh dalam mendapatkan informasi dan kegiatan penyuluhan http://indaharitonangfakultaspertanianunpad.blogspot.co.id/2013/06/metode-metode-p

Menurut hasil penelitian yang dilakukan Sharples (2003), penggunaan media website dapat menunjang proses penyuluhan jarak jauh yaitu penyuluhan kapan pun mereka inginkan, dengan cara apa pun, dan di mana pun mereka berada/berpergian. Studi yang dilakukan Motowalla (2007) menemukan bahwa aplikasi media informasi untuk penyuluh berbasis website dapat digunakan di dalam kelas atau dalam penyuluhan menggantikan penyuluhan di ruangan, tetapi jika keduanya digabungkan, penyuluhan mungkin menjadi lebih efektif dan fleksibel. Hal tersebut mengarah ke sebuah argumen bahwa proses penyuluhan penyuluh pertanian dengan menggunakan website bisa menjadi alternatif untuk mengatasi keterbatasan sarana informasi dan media penyuluhan untuk penyuluh pertanian.

Penyuluh pertanian dalam melaksanakan tugasnya dibatasi oleh suatu wilayah kerja penyuluh (WKP). Jumlah penyuluh pertanian yang ada di Kecamatan Berbak Kabupaten Tanjung Jabung Timur ada 7 orang yang masing-masing penyuluh pertanian memiliki handphoneyang dapat terkoneksi dengan internet. Sebagian besar penyuluh pertanian, petani dan gabungan kelompok tani (GAPOKTAN) dibawah bimbingan penyuluh pertanian sudah mulai menggunakan media website untuk mencari informasi bahkan beberapa GAPOKTAN melakukannya dengan memanfaatkan jaringan internet. Kondisi ini tentunya sangat berpengaruh terhadap kinerja penyuluh pertanian, yang sebagian besar masih menggunakan cara tradisional dalam melakukan kegiatan penyuluhan di lapangan. Hasil survey pendahuluan (2016) menunjukkan bahwa selama ini di kabupaten Tanjung Jabung belum ada website yang khusus dirancang untuk penyuluh pertanian dalam mencari informasi inovasi pertanian, kalaupun ada masih terbatas penggunaannya pada administrasi kelembagaan penyuluhan.

Kabupaten Tanjung Jabung Timur merupakan kabupaten yang sering mendapatkan bantuan ataupun program karena kabupaten ini merupakan lumbung pangan untuk provinsi Jambi. Direktorat Jenderal Prasarana dan Sarana Pertanian yang salah satu tugasnya adalah melaksanakan luas, maka masih sangat dimungkinkan untuk melaksanakan kegiatan perluasan areal tanaman pangan dengan menambah luasan/ baku lahan, melalui kegiatan perluasan areal tanaman pangan yang sering disebut dengan perluasan sawah.

Tujuan kegiatan perluasan sawah adalah melakukan kegiatan perluasan areal tanaman pangan dengan menambah luas baku lahan tanaman pangan, melalui kegiatan perluasan sawah. Sasaran areal perluasan sawah tahun 2010 - 2014 sesuai dengan Rencana Strategis (Renstra) Direktorat Jenderal Prasarana dan Sarana Pertanian sebesar 374.125 Ha, sedangkan sasaran areal perluasan sawah yang dapat dibiayai dari APBN per tahun tergantung pada dan yang tersedia. Manfaat program ini sangat membantu sekali masyarakat umumnya kecamatan Berbak karena sekarang ini masyarakat gencar memperluas perkebunan tetapi tidak sebagian masyarakat di kecamatan Berbak kabupaten Tanjung Jabung Timur.

Berdasarkan data yang diambil penyuluh di BP3K kecamatan Berbak terdapat program yang sudah dijalankan pada tahun 2012 ini yaitu program percetakan sawah baru yang terdapat di kelurahan Simpangkecamatan Berbakkabupaten Tanjung Jabung Timur. Program Percetakan Sawah Baru diadakan oleh pemerintah pada tahun 2006, namun Program Percetakan Sawah Baru ini mulai dilaksanakan oleh pemerintah Tanjung Jabung Timur dimulai pada tahun 2009 untuk kecamatan Berbak.

Penggunaan media penyuluhan berbasiswebsite bertujuan untuk mempermudah pekerjaan penyuluh pertanian dalam kegiatan penyuluhan kepada petani. Media yang digunakan adalah media yang mudah digunakan oleh penyuluh pertanian dengan latar belakang pendidikan, umur dan kondisi sosial budaya yang berbeda. Media website menjadi salah satu alternatif untuk mengatasi keterbatasan jumlah penyuluh pertanian dan luasnya wilayah penyuluhan.

Saat ini belum ada media website yang dirancang khusus untuk penyuluh pertanian di kecamatan berbak padahal media ini sangat membantu mempercepat program pemerintah yaitu program percetakan sawah baru. Media informasi berbasis websitesaat ini sedang mengalami perkembangan yang cukup pesat. Hal ini disebabkan karena kemampuan mediawebsitedalam proses penyebaran informasi yang cepat,mudah dibawa dan dapat dibuka untuk dibaca dan dipelajari sehingga penyuluh pertanian siap menyampaikan informasi kepada petani kapan dan dimanapun berada.

Peran penyuluh pertanian sangat diperlukan dalam pembangunan pertanian saat ini yang bertujuan untuk meningkatkan pengetahuan, keterampilan dan sikap petani sehingga dengan adanya penyuluh masalah yang dihadapi oleh petani dan upaya pemecahannya dapat diselesaikan. Selain itu penyuluh pertanian berfungsi sebagai perantara dalam proses penyebaran informasi, proses penerangan, proses 
perubahan perilaku dan proses pendidikan. Peran ini perlu ditopang dengan kemudahan penyuluh pertanian dalam mendapatkan informasi dan memperluas komunikasi dengan pihak lainnya yaitu peneliti, swasta maupun pihak lainnya yang ikut membantu tugas penyuluh.Berdasarkan latar belakang tersebut maka permasalahan yang akan diangkat dalam penelitian ini adalah : (1) Bagaimana cara mengembangkan media penyuluhan berbasis website sebagai media penyuluhan bagi penyuluh pertanian di kecamatan Berbak kabupaten Tanjung Jabung Timur, (2) Apa desain media penyuluhan berbasis website tentang program percetakan sawah baru untuk penyuluhan pertanian di kecamatan Berbak kabupaten Tanjung Jabung Timur. Penelitian ini bertujuan untuk mendapatkan desain media penyuluhan bagi penyuluh pertanian berbasis website tentang program percetakan sawah baru di kecamatan Berbak kabupaten Tanjung Jabung Timur. Hasil desain berbasis website ini dapat direkomedasikan kepada dinas pertanian kabupaten Tanjung Jabung Timur.

\section{METODE PENELITIAN}

\section{Ruang Lingkup Penelitian}

Penelitian dilakukan di kecamatan Berbak khususnya kelurahan simpang yang merupakan salah satu kelurahan yang menerapkan program percetakan sawah baru di Kabupaten Tanjung Jabung timur. Penentuan lokasi penelitian dilakukan secara sengaja (purposive) dengan pertimbangan bahwa bahwa kelurahan Simpang Kecamatan Berbak merupakan sentra penerapan program percetakan sawah baru di Kabupaten Tanjung jabung timur.

Ruang lingkup penelitian ini adalah untuk mendesain dan menentukan media yang paling efektif dalam penyampaian informasi tentang program percetakan sawah baru sehingga penyuluh termotivasi untuk mensosialisasikan program ini kepada petani. Jenis data yang digunakan dalam penelitian ini adalah data sekunder dan data primer. Data sekunder diperoleh dari studi literatur, laporan penelitian, jurnal ilmiah yang relevan dengan judul penelitian sedangkan data primer berasal dari hasil wawancara.

\section{Metode Penarikan sampel}

Sampel yang dijadikan dalam penelitian ini bertugas untuk melakukan uji coba yang telah dirancang oleh peneliti. Uji coba media bertujuan untuk melakukan pertimbangan, perbandingan untuk menilai media penyuluhan berbasis websiteyang telah dibuat. Subjek uji coba (responden) yang dipilih dalam penelitian ini adalah penyuluh pertaniankhususnya yang ada di kelurahan Simpang Kecamatan Berbak dan penyuluh pertanian yang ada Kabupaten Tanjung Jabung Timur yang pernah mengikuti sosialisasi program percetakan sawah baru. Pemilihan sampel penelitian ini dilakukan secara pruporsive karena penyuluh pertanian daerah penelitian ini merupakan penyuluh pertanian yang mengikuti sosialisasi program percetakan sawah baru, umur diatas 30 tahun, tidak buta warna dan minimal tamat SMP sehingga terpilih 32 orang PPL sebagai responden penelitian.

Metode Penelitian ini menggunakan metode Research and Development (penelitian dan pengembangan) dapat diartikan sebagai suatu proses atau langkah-langkah untuk mengembangkan suatu produk baru. Brog dan Gall dalam Sugiyono (2012) menyatakan "Bahwa penelitian pengembangan merupakan metode penelitian yang digunakan untuk mengembangkan atau memvalidasi produk-produk yang akan digunakan dalam pendidikan dan penyuluhan". Hal ini sejalan dengan yang diungkapkan oleh Sugiyono (2012), "Penelitian dan pengembangan atau Research and Development adalah metode penelitian yang digunakan untuk menghasilkan produk tertentu dan menguji keefektifan produk.

Penelitian pengembangan menghasilkan produk yang memiliki keefektifan sesuai dengan kegunaan produk tersebut pada suatu bidang tertentu, salah satunya pada bidang pertanian. Cara yang digunakan dalam penelitian ini untuk yaitu dengan mengembangkan produk media penyuluhan berbasis website khusus untuk penyuluh pertanian dalam membantu sosialisasi program percetakan sawah baru di Kecamatan Berbak. Kemudian produk yang sudah dikembangkan divalidasi, sehingga layak untuk digunakan sebagai media penyuluhan dan pembelajaran. 


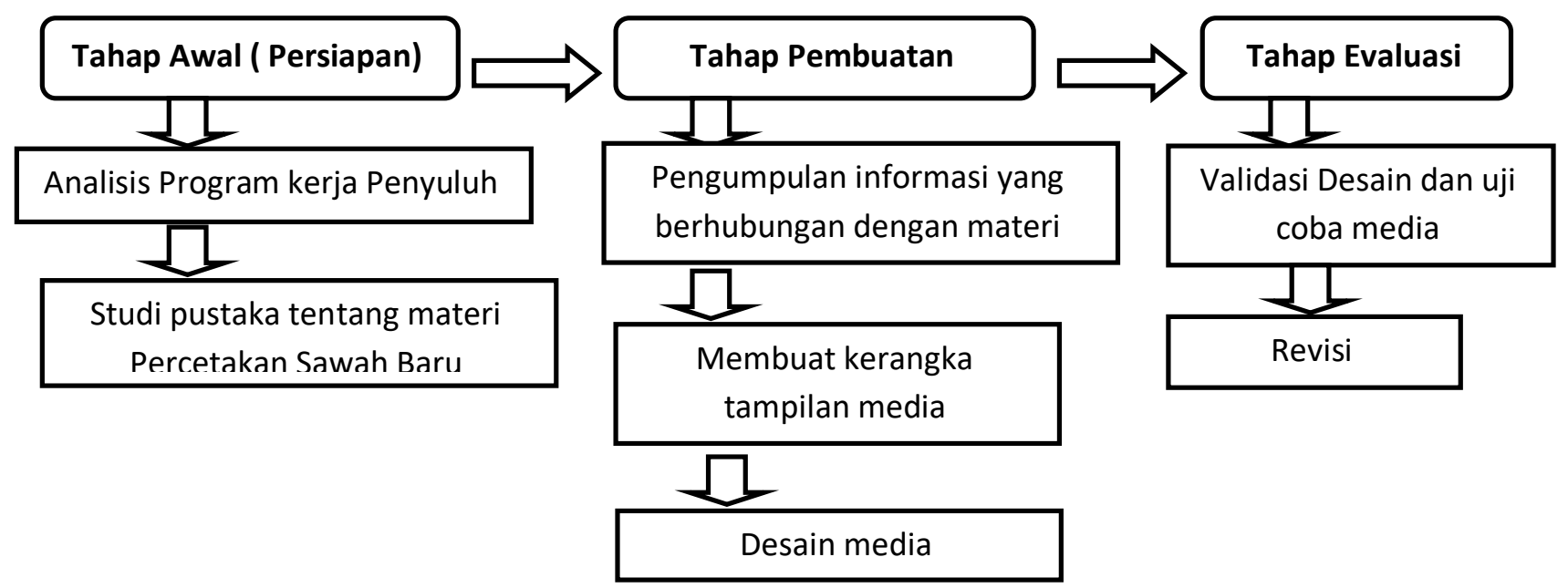

Gambar 1. Tahap pembuatan desain media penyuluhan berbasis website

Tahap desain media penyuluhan untuk penyuluh pertanian meliputi:

\section{Tahap Awal (Analisis dan Perancangan)}

Pada tahapan awal dilakukan pembuatan desain tampilan media yang meliputi Tahapan analisis yaitu : (1)menganalisa isi materi, materi untuk media penyuluhan berbasis website harus sinkron dengan tujuan pembuatan media penyuluhan dalam rangka mempermudah pekerjaan penyuluh dan mempercepat sosialisasi program percetakan sawah barusampai ke pelosok desa disekitar kecamatan Berbak, (2) Studi pustaka, yaitu mencari informasi baik melalui buku-buku ataupun dari sumber internet (website, blog dan lainnya), (3) Perancangan desain media penyuluhan dibuat berdasarkan tahapan yang dilakukan oleh peneliti.

\section{Tahap Pembuatan (Pengembangan)}

Pada tahapan pembuatan dilakukan tahapan sebagai berikut :

1. Pengumpulan bahan-bahan yang akan dimasukkan ke dalam media yang akan dibuat meliputi materi, gambar dan evaluasi

2. Membuat kerangka tampilan yang merupakan gambaran awal sebelum pembuatan media.

3. Pengembangan yaitu membuat media penyuluhan berbasis website sedemikian rupa sehingga sesuai dengan kerangka tampilan yang telah dibuat

4. Memisahkan topik-topik yang berkenaan dengan program percetakan sawah baru pada setiap pertemuan dalam folder dan membuat teks, animasi, simulasi dan gambar

\section{Tahap Evaluasi}

Tahap terakhir dalam penelitian yaitu evaluasi media yaitu proses untuk memperoleh variasi reaksi dari berbagai pihak terhadap desain media penyuluhan berbasis website yang telah dirancang. Evaluasi Menurut Belawati (2007) sangat diperlukan untuk melihat efektivitas penggunaan media penyuluhan berbasis website dalam membantu Penyuluh pertanian menyebarluaskan informasi kepada petani.

\section{Desain Uji coba media}

Desain media penyuluhan memiliki beberapa tahap yaitu sebagai berikut : Menyiapkan area kerja menggunakan Adobe Flash CS4 Professional : (1) Pada halaman utama, dibuat tombol pilihan yaitu : program percetakan sawah baru, Materi penyuluhan, Latihan, Bantuan, profil dan close, (2) Pada menu program percetakan sawah baru dapat dilihat apa, mengapa, siapa, kenapa dan bagaimana program percetakan sawah baru, (3) Pada menu materi penyuluhan berisikan materi-materi penyuluhan tentang program percetakan sawah baru yang akan disosialisasikan kepada petani, (3) Pada menu latihan berisikan pertanyaan pilihan sebagai bahan evaluasi, (4) Bantuan merupakan menu yang dibuat sebagai 
petunjuk penggunaan media yang dibuat yaitu menu profil menampilkan profil penulis yang membuat media dan menu close digunakan untuk keluar dari media.

\section{Teknik Pengumpulan data}

Pengumpulan data dalam penelitian ini dilaksanakan dengan cara sebagai berikut:

1) Tahap Persiapan terdiri dari : Mempersiapkan media penyuluhan berbasis website yang sesuai dengan hasil analisis audiens, menentukan tim ahli.

2) Tahap Pelaksanaan

Dalam penelitian ini peneliti menunjukkan hasil rancangan websiteyang telah selesai dibuat

kepada para tim ahli. Kemudian tim ahli memvalidasi media yang telah dibuat melalui angket

berstruktur dengan menyertakan saran dan masukan dalam perbaikan media.

3) Tahap Akhir

a. Membagikan angket tertutup kepada penyuluh pertanian yang berisi pernyataan-pernyataan sesuai dengan aspek kriteria pendidikan, tampilan program, dan kualitas teknis.

b. Menganalisis data kualitatif dan kuantitatif dari hasil yang diperoleh sesuai dengan teknik analisis data.

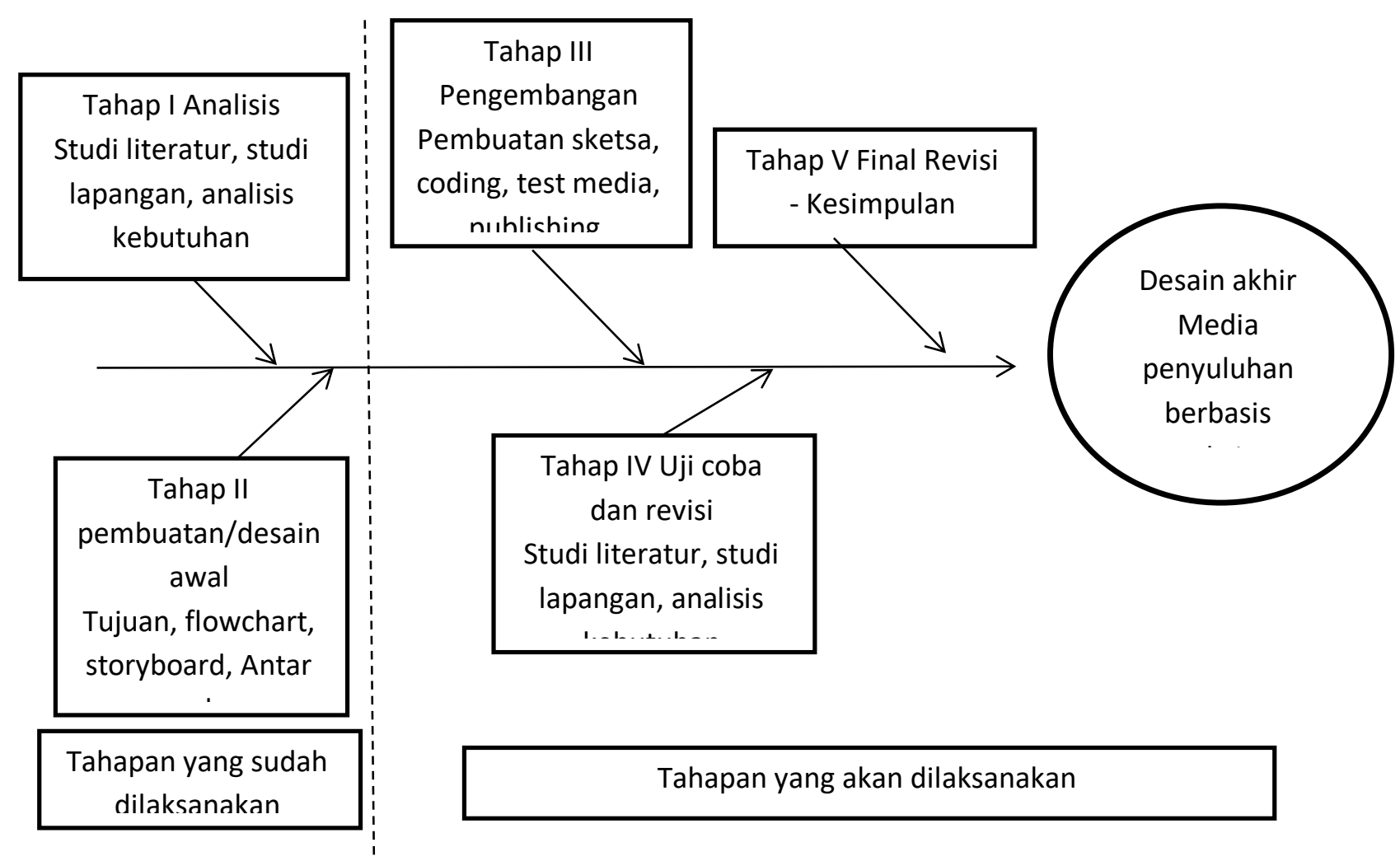

Gambar 2. bagan alir (fishbone) penelitian

\section{Teknik Analisis Data}

Teknik analisis data yang digunakan dalam penelitian ini adalah teknik triangulasi. Menurut Sugiyono (2011), "Triangulasi dalam pengujian kredibilitas diartikan sebagai pengecekan data dari berbagai sumber dengan berbagai cara dan berbagai waktu".

Data yang telah dikumpulkan disesuaikan dengan kebutuhan analisis, selanjutnya dilakukan analisis dengan menggunakan triangulasi sumber yaitu mengumpulkan saran dan pendapat dari 2 orang tim penilai tentang media penyuluhan yang telah dirancang. Data ini akan digunakan untuk memperbaiki media yang digunakan oleh penyuluh dalam kegiatan penyuluhan.

Penelitian ini dilakukan dengan menguji media tentang program percetakan sawah baru kepada penyuluh pertanian khususnya kelurahan Simpang Kecamatan Berbak Kabupaten Tanjung Jabung Timur. Selanjutnya dilakukan pengambilan data uji coba media kepada penyuluh pertanian dengan 
menyebarkan angket uji coba media penyuluhan berbasis website. Angket penelitian sebelum dilakukan penelitian diuji dengan menggunakan uji validitas dan realibilitas angket menggunakan responden penyuluh dari desa lain dalam kecamatan Berbak.

\section{HASIL DAN PEMBAHASAN}

\section{Penyajian Hasil Uji Coba}

Media penyuluhan berbasis website untuk penyuluh pertanian yang telah selesai dirancang, kemudian divalidasi oleh validator. Proses validasi media pembelajaran ini terdiri dari 3 orang validator, sedangkan dalam penyajian hasil uji coba terhadap validator digunakan teknik triangulasi sumber yaitu membandingkan 3 jawaban validator terhadap media yang telah dibuat. Dari hasil validasi yang telah dilakukan oleh validator dapat di lihat pada tahap-tahap berikut:

\section{Validasi Tahap I}

\section{a. Aspek media}

Tabel 1. Hasil triangulasi aspek media pada validasi tahap I

\begin{tabular}{|c|c|c|c|c|c|}
\hline No & Pernyataan & V. I & V. II & V. III & Hasil Triangulasi \\
\hline 1. & $\begin{array}{l}\text { Jenis huruf yang digunakan pada } \\
\text { media penyuluhan ini sudah } \\
\text { baik }\end{array}$ & $\sqrt{ }$ & $\sqrt{ }$ & $\sqrt{ }$ & $\begin{array}{l}\text { Tidak ada } \\
\text { revisi }\end{array}$ \\
\hline 2. & $\begin{array}{l}\text { Ukuran huruf yang digunakan } \\
\text { pada Media } \\
\text { sudah sesuai dan mudah dibaca. }\end{array}$ & $\sqrt{ }$ & $\sqrt{ }$ & $\sqrt{ }$ & $\begin{array}{l}\text { Tidak ada } \\
\text { revisi }\end{array}$ \\
\hline 3. & $\begin{array}{l}\text { Kombinasi warna huruf dengan } \\
\text { Background yang } \\
\text { media penyuluhan ini } r \\
\text { baik }\end{array}$ & $\mathrm{X}$ & $\mathrm{X}$ & $\sqrt{ }$ & Revisi terhadap background \\
\hline 4. & $\begin{array}{l}\text { Teks pada media penyuluhan } \\
\text { ini terbaca dengan baik. }\end{array}$ & $\sqrt{ }$ & $\sqrt{ }$ & $\sqrt{ }$ & $\begin{array}{l}\text { Re } \\
\text { visi terhadap teks yang } \\
\text { belum terbaca dengan } \\
\text { baik }\end{array}$ \\
\hline 5. & $\begin{array}{l}\text { Bahasa yang digunakan } \\
\text { baik dan benar }\end{array}$ & $\sqrt{ }$ & $\mathrm{X}$ & $\sqrt{ }$ & $\begin{array}{l}\text { Re } \\
\text { visi terhadap beberapa kata } \\
\text { Ya } \\
\text { ng masih susah untuk } \\
\text { dipahami. }\end{array}$ \\
\hline 6. & $\begin{array}{l}\text { Susunan kalimat pada slide yang } \\
\text { digunakan dalam } \\
\text { penyuluhan ini sudah baik. }\end{array}$ & $\mathrm{X}$ & $\mathrm{X}$ & $\sqrt{ }$ & $\begin{array}{l}\text { Re } \\
\text { visi terhadap kalimat yang } \\
\text { masih susah untuk dipahami. }\end{array}$ \\
\hline 7. & Tombol/ikon & $\sqrt{ }$ & $\sqrt{ }$ & $\sqrt{ }$ & $\begin{array}{l}\text { Tidak ada } \\
\text { revisi }\end{array}$ \\
\hline
\end{tabular}

\begin{tabular}{|c|c|c|c|c|c|}
\hline No & Pernyataan & V.I & V. II & V. III & Hasil Triangulasi \\
\hline & jelas. & & & & \\
\hline 8. & $\begin{array}{l}\text { Pemakaian Warna pada gambar } \\
\text { yang digunakan menarik. }\end{array}$ & $\sqrt{ }$ & $\sqrt{ }$ & $\sqrt{ }$ & Tidak ada revisi \\
\hline 9. & $\begin{array}{lll}\text { Ukuran dan kualitas gambar } \\
\text { yang digunakan sudah baik. }\end{array}$ & $\sqrt{ }$ & $\sqrt{ }$ & $\sqrt{ }$ & Tidak ada revisi \\
\hline 10 & \begin{tabular}{lll|}
$\begin{array}{l}\text { Keserasian } \\
\text { sudah baik. }\end{array}$ & Teks dan gambar \\
\end{tabular} & $\mathrm{X}$ & $\mathrm{X}$ & $\sqrt{ }$ & Revisi terhadap warna teks. \\
\hline 11 & $\begin{array}{lrr}\text { Keserasian } & \text { gambar } & \text { dengan } \\
\text { background } & \text { sudah } & \text { baik dan } \\
\text { henar } & & \end{array}$ & $\sqrt{ }$ & $\sqrt{ }$ & $\sqrt{ }$ & Tidak ada revisi \\
\hline
\end{tabular}




\begin{tabular}{|c|l|c|c|c|l|}
\hline 12 & $\begin{array}{l}\text { Kombinasi gambar dengan } \\
\text { animasi dan simulasi sudah baik }\end{array}$ & $\sqrt{ }$ & $\mathrm{X}$ & $\sqrt{ }$ & $\begin{array}{l}\text { Revisi terhadap warna dari } \\
\text { gambar serta ukurannya. }\end{array}$ \\
\hline 13 & $\begin{array}{l}\text { Animasi dan simulasi yang } \\
\text { digunakan menarik. }\end{array}$ & $\sqrt{ }$ & $\mathrm{X}$ & $\sqrt{ }$ & $\begin{array}{l}\text { Revisi terhadap partikel dari } \\
\text { animasi dan simulasi }\end{array}$ \\
\hline 14 & Suara video terdengar dengan jelas. & $\sqrt{ }$ & $\mathrm{X}$ & $\sqrt{ }$ & $\begin{array}{l}\text { Revisi terhadap suara pada } \\
\text { beberapa slide ditambahkan. }\end{array}$ \\
\hline
\end{tabular}

Berdasarkan hasil validasi tahap I pada aspek media penyuluhan diatas dapat disimpulkan bahwa valiadator I, revisi terhadap background, kalimat, serta warna teks. Pada validator ke II revisi terhadap background, kalimat, bahasa yang digunakan, warna gambar, partikel serta suara pada media dan validator III tidak ada revisi. Angket ahli media yang telah divalidasi dapat dilihat pada lampiran 3 .

\section{b. Aspek materi}

Tabel 2. Hasil triangulasi aspek materi pada validasi tahap I

\begin{tabular}{|c|c|c|c|c|c|}
\hline No & Pernyataan & V. I & V. II & V. III & Hasil Triangulasi \\
\hline 1. & $\begin{array}{l}\text { Materi pada media penyuluhan } \\
\text { ini sesuai dengan indikator }\end{array}$ & $\sqrt{ }$ & $\mathrm{X}$ & $\sqrt{ }$ & $\begin{array}{l}\text { Revisi } \text { deskripsi } \quad \text { mengena } \\
\text { Program percetakan sawah baru }\end{array}$ \\
\hline 2. & $\begin{array}{lrr}\text { Program } & \text { Media penyuluhan } \\
\text { Relevan } & \text { Dengan materi yang } \\
\text { harus dipelajari petani. }\end{array}$ & $\sqrt{ }$ & $\sqrt{ }$ & $\sqrt{ }$ & Tidak ada revisi \\
\hline 3. & $\begin{array}{l}\text { Bahasa yang digunakan mudah } \\
\text { dimengerti oleh petani }\end{array}$ & $\mathrm{X}$ & $\mathrm{X}$ & $\sqrt{ }$ & $\begin{array}{l}\text { Revisi terhadap penggunan } \\
\text { bahasa yang terlalu banyak. }\end{array}$ \\
\hline 4. & $\begin{array}{lrr}\text { Susunan } & \text { kalimat } & \text { pada media } \\
\text { Penyuluhan } & \text { ini } & \text { mengandung } \\
\text { nilai belajar bagi petani. }\end{array}$ & $\mathrm{X}$ & $\mathrm{X}$ & $\sqrt{ }$ & $\begin{array}{l}\text { Revisi terhadap susunan kalimat } \\
\text { yang masih kurang jelas. }\end{array}$ \\
\hline 5. & $\begin{array}{l}\begin{array}{l}\text { Media Penyuluhan ini } \\
\text { Mempermudah } \\
\text { menganalisa soal. }\end{array} \\
\text { dalam }\end{array}$ & $\sqrt{ }$ & $\sqrt{ }$ & $\sqrt{ }$ & Tidak ada revisi \\
\hline 6. & $\begin{array}{l}\text { Gambar yang ada pada media ini } \\
\text { sudah cocok dengan materi. }\end{array}$ & $\sqrt{ }$ & $\sqrt{ }$ & $\sqrt{ }$ & Tidak ada revisi \\
\hline 7. & $\begin{array}{llr}\text { simulasi } & \text { Pada } & \text { media } \\
\text { penyuluhan } & \text { inisesuai } & \text { dengan }\end{array}$ & $\sqrt{ }$ & $\mathrm{X}$ & $\sqrt{ }$ & Tambahkan simulasi \\
\hline
\end{tabular}

\begin{tabular}{|c|l|c|c|c|c|}
\hline No & \multicolumn{1}{|c|}{ Pernyataan } & V. I & V. II & V. III & Hasil Triangulasi \\
\hline 8. & $\begin{array}{l}\text { materi penyuluhan } \\
\text { penyn ini sesuai dengan } \\
\text { keaadaan sebenarnya. }\end{array}$ & $\sqrt{ }$ & $\sqrt{ }$ Yan terdapat dalam \\
\hline 9. & $\begin{array}{l}\text { Animasi g } \mathrm{g} \text { media penyuluhan ini dapat } \\
\text { menarik minat } \\
\text { Petani dan penyuluh untuk belajar }\end{array}$ & $\sqrt{ }$ & $\mathrm{X}$ & $\sqrt{ }$ & Tidak ada revisi \\
\hline 10. & $\begin{array}{l}\text { Gambar dan animasi pada media diuji } \\
\text { ini dapat menarik minat petani } \\
\text { dan mendorong motivasi belajar } \\
\text { Petani } \\
\text { f }\end{array}$ & $\sqrt{ }$ & $\mathrm{X}$ & $\sqrt{ }$ & Belum diuji \\
\hline
\end{tabular}


Berdasarkan hasil validasi tahap I pada aspek materi diatas dapat disimpulkan bahwa valiadator I, revisi terhadap penggunaan bahasa dan susunan kalimat. Pada validator ke II revisi terhadap penggunaan bahasa, revisi terhadap susunan kalimat, revisi ukuran gambar, simulasi, dan revisi. agar lebih bervariasi, sedangkan pada validator III tidak ada revisi.

\section{Validasi Tahap II}

\section{a. Aspek media}

Tabel 3. Hasil triangulasi aspek media pada validasi tahap II

\begin{tabular}{|c|c|c|c|c|}
\hline No & Pernyataan & $\begin{array}{c}\text { Validator } \\
\text { I }\end{array}$ & $\begin{array}{c}\text { Validator } \\
\text { II }\end{array}$ & Hasil Triangulasi \\
\hline 1. & $\begin{array}{lr}\text { Jenis Huruf } & \text { yang } \\
\text { digunakan Pada } & \text { media } \\
\text { penyuluhann ini } & \text { sudah } \\
\text { baik }\end{array}$ & $\sqrt{ }$ & $\sqrt{ }$ & Tidak ada revisi \\
\hline 2. & $\begin{array}{lrr}\text { Ukuran Huruf } & \text { yang } \\
\text { digunakan Pada } & \text { media } \\
\text { penyuluhan ini } & \text { sudah } \\
\text { sesuai dan } & \text { mudah dibaca. }\end{array}$ & $\sqrt{ }$ & $\sqrt{ }$ & Tidak ada revisi \\
\hline 3. & Kombinasi Warna huruf & $\sqrt{1}$ & $\mathrm{X}$ & Revisi beberapa warna teks \\
\hline
\end{tabular}




\begin{tabular}{|c|c|c|c|c|}
\hline No & Pernyataan & $\begin{array}{c}\text { Validator } \\
\text { I }\end{array}$ & $\begin{array}{c}\text { Validator } \\
\text { II }\end{array}$ & Hasil Triangulasi \\
\hline & \begin{tabular}{lrr}
\multicolumn{2}{l}{ dengan background yang } \\
$\begin{array}{l}\text { Digunakan } \\
\text { Penyuluhan }\end{array}$ \\
baik
\end{tabular} & & & \\
\hline 4. & $\begin{array}{l}\text { Teks pada media } \\
\text { penyuluhan ini terbaca } \\
\text { dengan baik. }\end{array}$ & $\sqrt{ }$ & $\sqrt{ }$ & Tidak ada revisi \\
\hline 5 . & $\begin{array}{l}\text { Bahasa yang digunakan } \\
\text { sudah baik dan benar }\end{array}$ & $\sqrt{ }$ & $\sqrt{ }$ & Tidak ada revisi \\
\hline 6. & 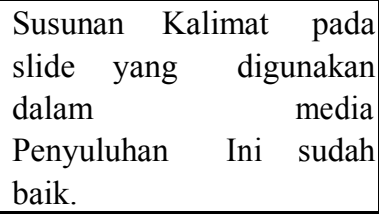 & $\sqrt{ }$ & $\mathrm{X}$ & $\begin{array}{l}\text { Revisi beberapa kalimat } \\
\text { yang masih belum jelas. }\end{array}$ \\
\hline 7. & $\begin{array}{ll}\text { Tombol/ikon terlihat } \\
\text { dengan jelas. }\end{array}$ & $X$ & $X$ & $\begin{array}{ll}\text { Tombol belum terlihat } \\
\text { dengan jelas. }\end{array}$ \\
\hline 8. & $\begin{array}{l}\text { Pemakaian warna pada } \\
\text { Gambar yang digunakan } \\
\text { menarik. }\end{array}$ & $\sqrt{ }$ & $\sqrt{ }$ & Tidak ada revisi \\
\hline 9. & 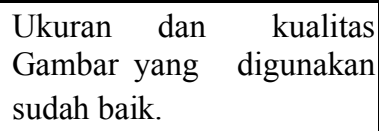 & $\mathrm{X}$ & $\mathrm{X}$ & Revisi ukuran gambar \\
\hline 10 & $\begin{array}{l}\text { Keserasian Teks } \\
\text { gambar sudah baik. }\end{array}$ & $\sqrt{ }$ & $\mathrm{X}$ & $\begin{array}{l}\text { Revisi terhadap warna teks } \\
\text { agar seresi dengan gambar. }\end{array}$ \\
\hline 11 & 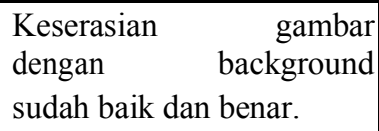 & $\sqrt{ }$ & $\sqrt{ }$ & Tidak ada revisi \\
\hline 12 & $\begin{array}{l}\text { Kombinasi } \\
\text { dengan Animasi dan } \\
\text { simulasi sudah baik }\end{array}$ & $\sqrt{ }$ & $\mathrm{X}$ & Diperbaiki lagi \\
\hline 13 & $\begin{array}{l}\text { Animasi dan simulasi } \\
\text { yang digunakan menarik. }\end{array}$ & $\sqrt{ }$ & $\sqrt{ }$ & Tidak ada revisi \\
\hline 14 & $\begin{array}{l}\text { Suara terdengar dengan } \\
\text { jelas. }\end{array}$ & $\sqrt{ }$ & $\sqrt{ }$ & Tidak ada revisi \\
\hline
\end{tabular}

Berdasarkan hasil validasi tahap II pada aspek media diatas dapat disimpulkan bahwa valiadator I, revisi terhadap tombol dan ukuran gambar, sedangkan pada validator ke II revisi terhadap warna teks, susunan kalimat, tombol, dan revisi terhadap kombinasi warna teks terhadap animasi. Angket ahli media yang telah divalidasi dapat dilihat pada lampiran 3. 
b. Aspek materi

Tabel 4. Hasil triangulasi aspek materi pada validasi tahap II

\begin{tabular}{|c|c|c|c|c|}
\hline No & Pernyataan & $\begin{array}{c}\text { Validator } \\
\text { I }\end{array}$ & $\begin{array}{c}\text { Validator } \\
\text { II }\end{array}$ & Hasil Triangulasi \\
\hline 1. & $\begin{array}{l}\text { Materi pada media } \\
\text { penyuluhann ini sesuai } \\
\text { dengan indikator }\end{array}$ & $\sqrt{ }$ & $\sqrt{ }$ & Tidak ada revisi \\
\hline 2. & $\begin{array}{lr}\text { Program } & \text { media } \\
\text { Penyuluhan relevan } \\
\text { Dengan materi } \\
\text { harus dipelajari petani. }\end{array}$ & $\sqrt{ }$ & $\sqrt{ }$ & Tidak ada revisi \\
\hline 3. & $\begin{array}{l}\text { Bahasa yang digunakan } \\
\text { mudah dimengerti oleh } \\
\text { petani. }\end{array}$ & $\sqrt{ }$ & $\sqrt{ }$ & Tidak ada revisi \\
\hline 4. & $\begin{array}{l}\text { Susunan kalimat pada } \\
\text { media penyuluhan ini } \\
\text { Mengandung nilai } \\
\text { belajar bagi petani. }\end{array}$ & $\sqrt{ }$ & $\mathrm{X}$ & $\begin{array}{l}\text { Gunakan susunan kalimat } \\
\text { yang lebih baik. }\end{array}$ \\
\hline 5. & $\begin{array}{l}\text { Media penyuluhan ini } \\
\text { Mempermudah dalam } \\
\text { Menganalisa } \\
\text { kasus. }\end{array}$ & $\sqrt{ }$ & $\sqrt{ }$ & Tidak ada revisi \\
\hline 6. & $\begin{array}{l}\text { Gambar yang ada pada } \\
\text { media ini sudah cocok } \\
\text { dengan materi } \\
\text { penyuluhan }\end{array}$ & $\sqrt{ }$ & $\mathrm{X}$ & Revisi terhadap grafik \\
\hline 7. & $\begin{array}{l}\text { simulasi pada media } \\
\text { penyuluhan ini sesuai } \\
\text { dengan materi } \\
\text { penyuluhan. }\end{array}$ & $\sqrt{ }$ & $\mathrm{X}$ & $\begin{array}{l}\text { Revisi terhadap grafik pada } \\
\text { simulasi }\end{array}$ \\
\hline 8. & $\begin{array}{lc}\text { Gambar Dan } & \text { animasi } \\
\text { pada } & \text { media } \\
\text { penyuluhan ini } & \text { sesuai } \\
\text { Dengan } & \text { keaadaan } \\
\text { sebenarnya. } & \\
\end{array}$ & $\sqrt{ }$ & $\mathrm{X}$ & $\begin{array}{l}\text { Revisi gambar agar terlihat } \\
\text { jelas }\end{array}$ \\
\hline 9. & 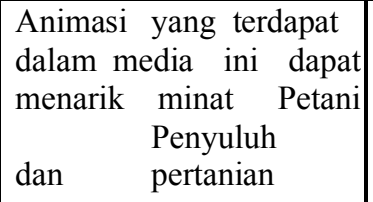 & $\sqrt{ }$ & $\sqrt{ }$ & Tidak ada revisi \\
\hline 10. & 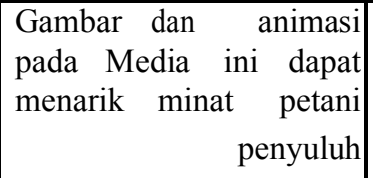 & $\sqrt{ }$ & $\sqrt{ }$ & Tidak ada revisi \\
\hline
\end{tabular}


Berdasarkan hasil validasi tahap II pada aspek materi diatas dapat disimpulkan bahwa valiadator I tidak terdapat revisi, sedangkan pada validator ke II revisi terhadap susunan kalimat, revisi terhadap grafik dan gambar pada simulasi.

\section{Validasi Tahap III}

a. Aspek media

Tabel 5 Hasil triangulasi aspek media pada validasi tahap III

\begin{tabular}{|c|c|c|c|c|}
\hline No & Pernyataan & $\begin{array}{l}\text { Validator } \\
\text { I }\end{array}$ & $\begin{array}{l}\text { Validator } \\
\text { II }\end{array}$ & Hasil Triangulasi \\
\hline 1. & $\begin{array}{lrr}\text { Jenis } & \text { huruf } & \text { yang } \\
\text { digunakan pada } & \text { media } \\
\text { Penyuluhan } & \text { ini } & \text { sudah } \\
\text { Baik } & & \end{array}$ & $\sqrt{ }$ & $\sqrt{ }$ & Tidak ada revisi \\
\hline 2. & \begin{tabular}{lrr} 
Ukuran huruf & yang \\
digunakan pada & media \\
Penyuluhann ini & sudah \\
\multicolumn{3}{l}{ sesuai dan mudah dibaca. }
\end{tabular} & $\sqrt{ }$ & $\sqrt{ }$ & Tidak ada revisi \\
\hline 3. & $\begin{array}{lcc}\text { Kombinasi } & \text { warna } & \text { huruf } \\
\text { dengan background yang } \\
\text { digunakan } & \text { media } \\
\text { Penyuluhan } & \text { ini } & \text { sudah } \\
\text { Baik } & & \end{array}$ & $\sqrt{ }$ & $\sqrt{ }$ & Tidak ada revisi \\
\hline 4. & $\begin{array}{l}\text { Teks Pada media } \\
\text { penyuluhan ini terbaca } \\
\text { dengan baik. }\end{array}$ & $\sqrt{ }$ & $\sqrt{ }$ & Tidak ada revisi \\
\hline 5. & $\begin{array}{l}\text { Bahasa Yang digunakan } \\
\text { sudah baik dan benar }\end{array}$ & $\sqrt{ }$ & $\sqrt{ }$ & Tidak ada revisi \\
\hline 6. & $\begin{array}{lcc}\text { Susunan } & \text { kalimat } & \text { pada } \\
\text { slide yang } & \text { digunakan } \\
\text { Dalam } & & \text { media } \\
\text { Penyuluhan } & \text { ini } & \text { sudah } \\
\text { baik. } & & \end{array}$ & $\sqrt{ }$ & $\sqrt{ }$ & Tidak ada revisi \\
\hline 7. & $\begin{array}{ll}\text { Tombol/ikon } & \text { terlihat } \\
\text { dengan jelas. }\end{array}$ & $\sqrt{ }$ & $\sqrt{ }$ & Tidak ada revisi \\
\hline 8. & $\begin{array}{l}\text { Pemakaian warna pada } \\
\text { Gambar yang digunakan } \\
\text { menarik. }\end{array}$ & $\sqrt{ }$ & $\sqrt{ }$ & Tidak ada revisi \\
\hline 9. & 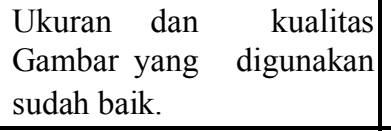 & $\sqrt{ }$ & $\sqrt{ }$ & Tidak ada revisi \\
\hline 10 & $\begin{array}{l}\text { Keserasian teks dan } \\
\text { gambar sudah baik. }\end{array}$ & $\sqrt{ }$ & $\sqrt{ }$ & Tidak ada revisi \\
\hline
\end{tabular}




\begin{tabular}{|c|c|c|c|c|}
\hline No & Pernyataan & $\begin{array}{c}\text { Validator } \\
\text { I }\end{array}$ & $\begin{array}{c}\text { Validator } \\
\text { II }\end{array}$ & Hasil Triangulasi \\
\hline 11 & $\begin{array}{l}\text { Keserasian gambar } \\
\text { dengan background } \\
\text { sudah baik dan benar. }\end{array}$ & $\sqrt{ }$ & $\sqrt{ }$ & Tidak ada revisi \\
\hline 12 & $\begin{array}{lr}\text { Kombinasi } & \text { gambar } \\
\text { dengan } & \text { animasidan } \\
\text { Sumulasi } & \\
\end{array}$ & $\sqrt{ }$ & $\sqrt{ }$ & Tidak ada revisi \\
\hline 13 & $\begin{array}{l}\text { Animasi Dan simulasi } \\
\text { yang digunakan menarik. }\end{array}$ & $\sqrt{ }$ & $\sqrt{ }$ & Tidak ada revisi \\
\hline 14 & $\begin{array}{l}\text { Suara Trdengar dengan } \\
\text { jelas. }\end{array}$ & $\sqrt{ }$ & $\sqrt{ }$ & Tidak ada revisi \\
\hline
\end{tabular}

Berdasarkan hasil validasi tahap III pada aspek media penyuluhan diatas dapat disimpulkan bahwa valiadator I dan II tidak terdapat lagi revisi, sehingga media dapat diujicobakan.

\section{b. Aspek materi}

Tabel 6. Hasil triangulasi aspek materi pada validasi tahap III

\begin{tabular}{|c|c|c|c|c|}
\hline No & Pernyataan & $\begin{array}{c}\text { Validator } \\
\text { I }\end{array}$ & $\begin{array}{c}\text { Validator } \\
\text { II }\end{array}$ & Hasil Triangulasi \\
\hline 1. & $\begin{array}{l}\text { Materi Pada media } \\
\text { penyuluhan ini sesuai } \\
\text { dengan indicator }\end{array}$ & $\sqrt{ }$ & $\sqrt{ }$ & Tidak ada revisi \\
\hline 2. & $\begin{array}{lr}\begin{array}{l}\text { Program } \\
\text { Penyuluhan }\end{array} & \text { media } \\
\text { dengan } \quad \text { Materi } & \text { yang } \\
\text { harus dipelajari petani. } & \\
\end{array}$ & $\sqrt{ }$ & $\sqrt{ }$ & Tidak ada revisi \\
\hline 3. & $\begin{array}{lr}\text { Bahasa } & \text { yang } \\
\text { Digunakan } & \text { mudah } \\
\text { dimengerti oleh penyuluh }\end{array}$ & $\sqrt{ }$ & $\sqrt{ }$ & Tidak ada revisi \\
\hline 4. & $\begin{array}{l}\text { Susunan kalimat pada } \\
\text { media penyuluhan ini } \\
\text { Mengandung } \\
\text { belajar bagi penyuluh }\end{array}$ & $\sqrt{ }$ & $\sqrt{ }$ & Tidak ada revisi \\
\hline 5. & $\begin{array}{lr}\text { Media } & \text { penyuluhan } \\
\text { Ini } & \text { mempermudah } \\
\text { Dalam } & \text { menganalisa } \\
\text { kasus. } & \\
\end{array}$ & $\sqrt{ }$ & $\sqrt{ }$ & Tidak ada revisi \\
\hline 6. & $\begin{array}{l}\text { Gambar yang ada pada } \\
\text { media ini sudah cocok } \\
\text { dengan materi } \\
\text { penyuluhan }\end{array}$ & $\sqrt{ }$ & $\sqrt{ }$ & Tidak ada revisi \\
\hline 7. & $\begin{array}{ll}\text { simulasi Pada } & \text { media } \\
\text { penyuluhan ini sesuai } & \\
\text { dengan } & \text { materi } \\
\end{array}$ & $\sqrt{ }$ & $\sqrt{ }$ & Tidak ada revisi \\
\hline
\end{tabular}




\begin{tabular}{|c|c|c|c|c|}
\hline No & Pernyataan & $\begin{array}{c}\text { Validator } \\
\text { I }\end{array}$ & $\begin{array}{c}\text { Validator } \\
\text { II }\end{array}$ & Hasil Triangulasi \\
\hline & penyuluhan. & & & \\
\hline 8. & $\begin{array}{lr} & \mathrm{Da} \\
\text { Gambar } \mathrm{n} & \text { animasi } \\
\text { Pada } & \text { media } \\
\text { penyuluhan ini sesuai } \\
\text { dengan } & \text { keaadaan } \\
\text { sebenarnya. } & \\
\end{array}$ & $\sqrt{ }$ & $\sqrt{ }$ & Tidak ada revisi \\
\hline 9. & $\begin{array}{lr}\text { Animasi yang terdapat } \\
\text { dalam media ini dapat } \\
\text { menarik } & \text { minat Petani } \\
\text { Dan } & \text { Mendorong } \\
\text { motivasi } & \text { penyuluh }\end{array}$ & $\sqrt{ }$ & $\sqrt{ }$ & Tidak ada revisi \\
\hline 10. & $\begin{array}{l}\text { Gambar Dan animasi } \\
\text { Pada Media ini dapat } \\
\text { menarik minat Petani } \\
\text { Dan Mendorong } \\
\text { Motivasi penyuluh. }\end{array}$ & $\sqrt{ }$ & $\sqrt{ }$ & Tidak ada revisi \\
\hline
\end{tabular}

Berdasarkan hasil validasi tahap III pada aspek materi diatas dapat disimpulkan bahwa valiadator I dan II tidak terdapat lagi revisi, sehingga media sudah dapat diujicobakan.

Setelah media selesai divalidasi selanjutnya dilakukan proses uji coba kelayakan media. Proses uji coba kelayakan media dilakukan dengan cara menyebarkan angket tertutup kepada responden (siswa). Sebelum angket disebarkan terlebih dahulu dilakukan uji coba angket. Pada uji coba angket ini terdapat 10 item pertanyaan. Dari ujicoba angket ini diperoleh ke-10 item valid. Angket yang sudah dinyatakan valid selanjutnya digunakan untuk uji kelayakan media. Angket uji kelayakan media ini disebarkan kepada penyuluh pertanian dengan jumlah 32 orang.

\section{Analisis Data}

Media yang sudah jadi kemudian divalidasi oleh 3 validator menggunakan teknik triangulasi sumber yaitu pengecekan terhadap media dengan beberapa sumber yang berbeda. Dari 3 validator ini ditemukan beberapa saran tentang perbaikan media yang dapat dilihat pada revisi produk. Pengumpulan saran ini dilakukan beberapa kali sampai tim validator menyatakan media penyuluhanini telah layak untuk diuji cobakan.

Media penyuluhan ini kemudian diujicobakan kepada penyuluh untuk mengetahui kelayakan media penyuluhan yang telah didesain dengan menggunakan angket tertutup. Dari hasil angket yang diisi oleh penyuluh sebagai responden didapatkan hasil analisis skor sebagai berikut:

Tabel 7. Persentase angket persepsi siswa tentang efektivitas multimedia

\begin{tabular}{|c|l|c|c|c|c|}
\hline No & \multicolumn{1}{|c|}{ Pernyataan } & $\begin{array}{c}\text { Item } \\
\text { Soal }\end{array}$ & Skor & Persentase & Kategori \\
\hline 1. & $\begin{array}{l}\text { Isi media sesuai dengan tujuan } \\
\text { penyuluhan. }\end{array}$ & 1 & 112 & $72,25 \%$ & Baik \\
\hline 2. & $\begin{array}{l}\text { Isi media sudah relevan dengan materi } \\
\text { yang dipelajari. }\end{array}$ & 2 & 132 & $85,16 \%$ & $\begin{array}{c}\text { Sangat } \\
\text { Baik }\end{array}$ \\
\hline 3. & $\begin{array}{l}\text { Isi media mudah untuk dimengerti dan } \\
\text { dipahami. }\end{array}$ & 3 & 118 & $76,12 \%$ & Baik \\
\hline & Isi media sesuai denganmateri & & & &
\end{tabular}



eISSN: 2621-1300 (e); 2621-1297 (p), Volume 1. no (1) 2018

\begin{tabular}{|c|l|c|c|c|c|} 
4. & Penyuluha & 4 & 129 & $83,22 \%$ & Baik \\
\hline 5. & $\begin{array}{l}\text { Media dapat digunakan dengan mudah } \\
\text { dan fleksibel. }\end{array}$ & 5 & 126 & $81,29 \%$ & Baik \\
\hline 6. & $\begin{array}{l}\text { Media menyajikan tampilan (warna, } \\
\text { juruf, gambar, animasi) yang baik dan } \\
\text { menarik. }\end{array}$ & 6 & 119 & $76,77 \%$ & Baik \\
\hline 7. & $\begin{array}{l}\text { Penggunaan media sebagai media } \\
\text { memperoleh informasi materi penyuluhan } \\
\text { menalu }\end{array}$ & 7 & 125 & $80,64 \%$ & Baik \\
\hline 8. & $\begin{array}{l}\text { Media dapat digunakan sebagai media } \\
\text { Penyuluhan pertanian }\end{array}$ & 8 & 123 & $79,35 \%$ & Baik \\
\hline
\end{tabular}


Tabel 8. Persentase angket persepsi penyuluh tentang motivasi untuk melakukan kegitan penyuluhan

\begin{tabular}{|c|c|c|c|c|c|}
\hline No & Pernyataan & $\begin{array}{l}\text { Item } \\
\text { Soal }\end{array}$ & Skor & Persentase & Kategori \\
\hline 1. & $\begin{array}{lccr}\text { Penggunaan } \quad \text { Media } & \text { Sebagai } & \text { media } \\
\text { Penyuluhan Membuat } & \text { Penyulu } & \text { lebih } \\
\text { bersemangat untuk } & & \\
\text { melakukan penyuluhan. } & & \end{array}$ & 9 & 115 & $74,19 \%$ & Baik \\
\hline 2. & $\begin{array}{l}\text { Media sebagai media Penyuluhan } \\
\text { membuat penyuluh lebih tertarik untuk } \\
\text { memberikan penyuluhan }\end{array}$ & 10 & 115 & $74,19 \%$ & Baik \\
\hline 3. & $\begin{array}{l}\text { Pengunaan Media } \quad \text { Sebagai } \\
\text { penyuluhan merangsang rasa ingin tahu } \\
\text { penyuluh. }\end{array}$ & 11 & 122 & $78,70 \%$ & Baik \\
\hline 4. & $\begin{array}{lcr}\text { Penggunaan } & \text { Media } & \text { Penyuluhan } \\
\text { Dapat meningkatkan perhatian penyuluh } \\
\text { Untuk } & \text { Kegiatan } & \text { penyuluhan }\end{array}$ & 12 & 115 & $74,19 \%$ & Baik \\
\hline \multicolumn{4}{|c|}{ Rata-rata } & $75,31 \%$ & Baik \\
\hline
\end{tabular}

Tabel 9. Persentase angket persepsi penyuluh tentang kegiatan penyuluhan

\begin{tabular}{|c|l|c|c|c|c|}
\hline No & \multicolumn{1}{|c|}{ Pernyataan } & $\begin{array}{l}\text { Item } \\
\text { Soal }\end{array}$ & Skor & Persentase & Kategori \\
\hline 1. & $\begin{array}{l}\text { Media sebagai media penyuluhan } \\
\text { dapat membuat penyuluh belajar mandiri. }\end{array}$ & 13 & 117 & $75,48 \%$ & Baik \\
\hline 2. & $\begin{array}{l}\text { Media sebagai media Penyuluhan } \\
\text { dapat meningkatkan partisipasi penyuluh dalam } \\
\text { pembelajaran }\end{array}$ & 14 & 119 & $76,77 \%$ & Baik \\
\hline 3. & $\begin{array}{l}\text { Media sebagai media penyuluhan } \\
\text { membantu penyuluh menyelesaikan persoalan } \\
\text { yang muncul dalam penyuluhan. }\end{array}$ & 15 & 120 & $77,41 \%$ & Baik \\
\hline \multicolumn{4}{|r|}{ Rata-rata } & $\mathbf{7 6 , 5 5 \%}$ & Baik \\
\hline
\end{tabular}

Berdasarkan hasil analisis data angket persepsi penyuluh yang telah disebarkan, media penyuluhan ini mempunyai aspek efektivitas 79,35\% (Baik), aspek motivasi belajar 75,31\% (Baik), dan aspek aktifitas penyuluhan penyuluh 76,55\% (Baik). Dari data di atas dapat disimpulkan bahwa media penyuluhan ini mempunyai efektivitas yang baik serta dapat meningkatkan motivasi dan aktifitas belajar penyuluh pertanian terhadap kegiatan penyuluhan. 


\section{Revisi Produk}

Revisi produk dilakukan beberapa kali sesuai saran dari validator. Validasi oleh validator pertama dilakukan sebanyak 3 kali dengan dua kali revisi dan validasi oleh validator kedua dilakukan sebanyak 3 kali dengan dua kali revisi. Hal-hal yang direvisi antara lain ukuran huruf, warna teks, gambar, konsep, animasi, variasi soal-soal latihan. Adapun revisi yang disarankan oleh validator adalah sebagai berikut:

\section{a. Aspek media}

Aspek media yang direvisi adalah background, tombol/ikon, ukuran gambar, dan animasi. Berikut ini beberapa halaman media yang direvisi:

Gambar 4.1

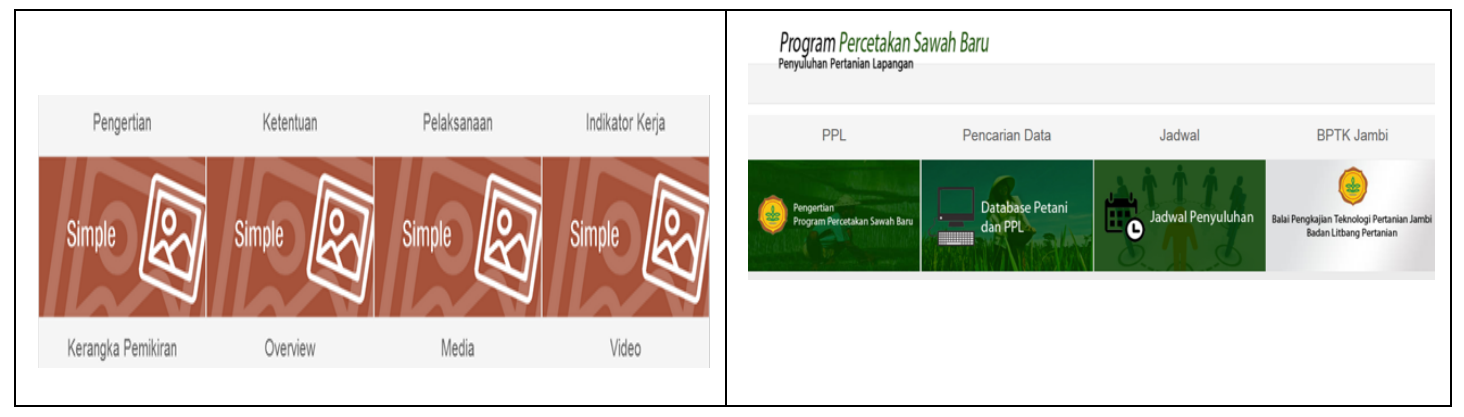

\section{Sebelum revisi}

\section{Sesudah revisi}

b. Aspek materi

Gambar 4.2 Revisi pada warna gambar dan tombol/ikon

Aspek materi yang direvisi adalah tambahan materi agar lebih mudah dipahami dan penambahan konsep pada animasi. Berikut ini beberapa materi pada media pembelajaran yang direvisi:

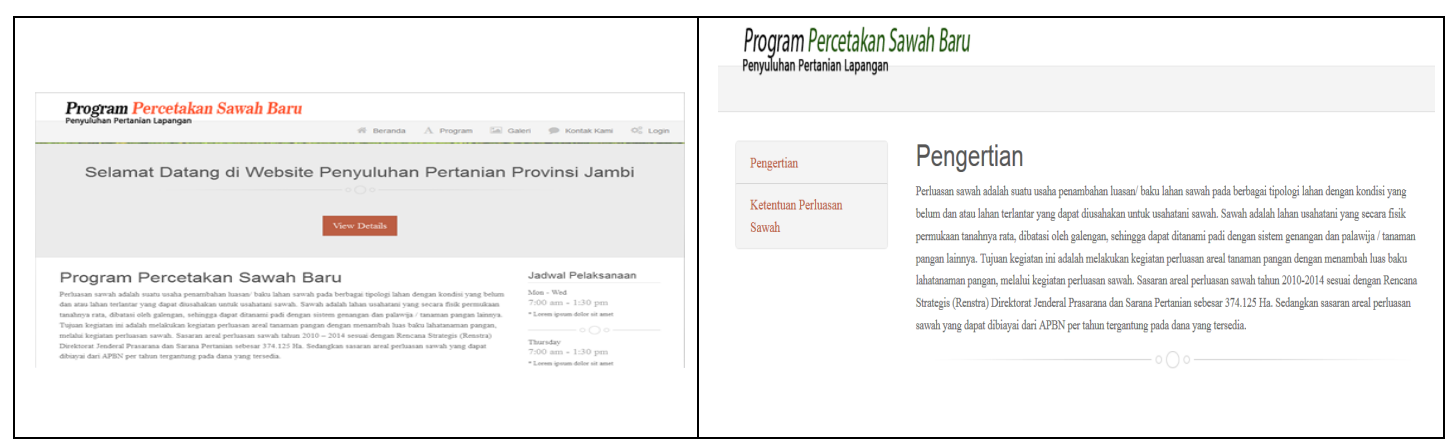

Sebelum revisi

Sesudah revisi

Gambar 4.3 Revisi pada mater

\section{Kesimpulan}

1. Cara yang digunakan untuk mengembangkan media penyuluhan untuk penyuluh pertanian berbasis website sebagai media penyuluhan pertanian di kecamatan berbak adalah dengan menggunakan metode penelitian dan pengembangan. Pada tahap awal penelitian ini dilakukan pembuatan sketsa media, coding, test media, publishing. Tahap 
kedua dilakukan uji coba dan revisi, studi literatur, studi lapangan, analisis kebutuhan. Tahap kedua dilakukan finalisasi media yaitu melakukan revisi terhadap media yang telah di dilakukan penilaian oleh kelompok ahli dari bidang desain media, isi media dan tampilan media yang berasal dari akademisi, pemerintah dan pengguna yaitu penyuluh.

2. Desain media penyuluhan berbasis website tentang program percetakan sawah baru untuk penyuluhan pertanian di kecamatan Berbak kabupaten Tanjung Jabung Timur menggunakan gabungan teks, gambar, suara, grafik, warna dan animasi atau desain multimedia berbasis website. Fasilitas yang ada pada

\section{Saran} website menu beranda, program, informasi, kontak kami dan log in.

1. Pada penelitian selanjutnya disarankan untuk dapat menguji pengaruh penggunaan media penyuluhan dalam bentuk media cetak seperti buklet, leflet dan koran

2. Media penyuluhan ini dapat ini dapat dijadikan sebagai variasi sarana penyuluhandalam rangka meningkatkan kreativitas dan motivasi penyuluh

3. Media penyuluhan ini dapat dijadikan sebagai alternatif pembelajaran mandiriyang dapat digunakan petani jika terkedala oleh jarak dan waktu.

4. Sebagai bahan pembanding untuk menghasilkan media penyuluhan yang lebihbaik dan lebih sempurna lagi sehingga dapat menambah minat dan motivasi penyuluh dalam melakukan penyuluhan kepada petani

\section{DAFTAR PUSTAKA}

Anwas EOM. 2009. Pemanfaatan media dalam pengembangan kompetensi penyuluh pertanian. [disertasi]. Bogor (ID): Institut Pertanian Bogor. 230 hal.

Anonim, 2012. Media Penyuluhan. Badan Pelaksana Penyuluhan Kabupaten Sragen

Arsyad. 2009. Pengantar Teknologi Informasi. Yogyakarta (ID): Graha Ilmu.

BP3K Kecamatan Berbak. Kelompok tani, jumlah anggota, luas usahatani padi sawah kelurahan simpang 2011. Jambi.

E.O. M. Anwas, Sumardjo, P.S. Asngari dan P. Tjitropranoto. 2009. Faktor-faktor yang mempengaruhi pemanfaatan media. Jurnal komunikasi pembangunan 7 (2) : 68-81

http://indaharitonang-fakultaspertanianunpad.blogspot.co.id/2013/06/metode-metodepenelitian

Huseini, 2006. Pengantar Teknologi informasi. Graha Ilmu, Yogyakarta.

Jihad. 2010. Evaluasi pembelajaran. Yogyakarta: Multi Persada

Pedoman Perluasan Sawah. 2012. Dinas Pertanian Tanaman Pangan. Laporan Tahunan Provinsi Jambi. Jambi

Rudi Brets, 2008. Media penyuluhan. Rajawali Press, Jakarta

Sadiman, 2009. Media dan metode penyuluhan. Rajawali Press, Jakarta

Sugiyono. 2012. Metode Penelitian Pendidikan. Alvabeta: Bandung

Suhardiyono. 1999. Fungsi pelayanan penyuluhan. Bumi Aksara: Jakarta

Sankarto, et al, 2002. Media penyuluhan pertanian. PT. Gramedia, Jakarta.

Susanto, 2008. Peranan Penyuluhan Pembangunan dalam Meningkatkan kualitas SDM. Dalam pemberdayaan Manusia pembangunan yang bermartabat. Pustaka Bangsa Press. Institut Pertanian Bogor.

Soekartawi. 2004. Prinsip Dasar Komunikasi Pertanian. Universitas Indonesia

Van den Ban, AW, Hawkins, HS, 1999. Penyuluhan pertanian. Kanisius Yogyakarta. 


\section{Ucapan Terima kasih}

Ucapan terima kasih penulis sampaikan kepada :

1. Ketua lembaga penelitian Universitas Jambi yang telah memberikan bantuan dana penelitian kepada penulis

2. Dekan Fakultas Pertanian Universitas Jambi yang telah memberikan dana penelitian dari anggaran Fakultas Pertanian UNJA kepada penulis dan dukungan sertakesempatan kepada penulis sehingga berhasil mendapatkan bantuan penelitian

3. Ketua dan anggota kelompok tani kakao di desa Betung Kecamatan Kumpeh Kabupaten Muaro Jambi 